\title{
TRASCENDENCIA Y REGENERACIÓN EN LA POESÍA DE DAVID ROSENMANN-TAUB
}

\author{
Naín Nómez \\ Universidad de Santiago de Chile \\ Santiago, Chile \\ nain.nomez@usach.cl
}

\begin{abstract}
RESUMEN / ABSTRACT
Esta presentación se focaliza en las diversas maneras que tiene(n) el (o los) sujeto(s) poético(s) de la tetralogía Cortejo y epinicio de David Rosenmann-Taub, para actualizar en la memoria la necesidad de una trascendencia que se focaliza en la búsqueda del origen y la regeneración de la vida, aspiraciones que se representan como deseo de exorcizar la muerte. Este deseo que forma parte del imaginario poético de Rosenmann-Taub establece una genealogía con las fuentes estéticas de los vanguardistas, fuentes que son resignificadas en su obra, a través de una multiplicidad de estrategias discursivas. En este mismo sentido, se articula con las neovanguardias de los años 50 (del siglo XX) en Chile y el continente, a partir de una tensión irresuelta entre la búsqueda de lo trascendental y la imposibilidad de lograrlo. Esto conduce al sujeto poético al deseo de una humanización del mundo a partir de la búsqueda de la trascendencia en la divinidad, el amor y la belleza, por un lado, y a la inmersión en el dolor, la desesperación y la vacuidad existencial, por otro.
\end{abstract}

PALABRAS CLAVE: neovanguardia, trascendencia, regeneración, poesía.

\section{TRASCENDENCE AND REGENERATION IN DAVID ROSENMANN-TAUB'S POETRY}

This work it focalizes into the different ways that the poetic subject(s)in Cortejo y epinicio tetralogy of David Rosenmann-Taub, have to actualized in the memory, the need for a transcendence that is focalize in the search for the source and life's regeneration, aspirations that are represented as a desire to exorcize death. This imaginary desire, articulate the poetic production of Rosenmann-Taub, with the aesthetical sources of the avant-gardists, sources that are resignified in it work, through a multiplicity of discourse strategies. In this way, it is articulated with the neo avant-gardes from the fifties (from XX century) in Chile and the continent, according to a insoluble tension between the transcendence search and the impossibility to get it. All this, conduct the poetic subject to the wish for the humanization or 
world through the search of divinity, love and beauty by one side; and to pain, desperation and existential emptiness for the other.

KEYWORDS: neo avant-garde, trascendence, regeneration, poetry.

Recepción: 28/03/2018

Aprobación: 18/06/2018

\section{EL CONTEXTO HISTÓRICO-LITERARIO}

Es necesario considerar que la poesía de David Rosenmann-Taub (1927-), se entronca, al mismo tiempo que se separa, de una amplia cohorte de poetas, cuya producción se inicia alrededor de los años cuarenta del siglo XX en Chile y cuya matriz central es la ruptura con las vanguardias, ruptura que se da a veces de manera central como en el caso del poeta Nicanor Parra y en otras, de forma más tangencial o parcial, como ocurre con líricos como Gonzalo Rojas, Jorge Teillier, Efraín Barquero, Enrique Lihn y el propio poeta que nos ocupa. Sin esta intencionalidad estética a la vista, resulta difícil enfocar su proyecto poético, que surge dentro de una constelación mayor de autores cuya influencia dura hasta nuestros días ${ }^{1}$.

Sabemos que en esos años, la producción estética de poetas como Pablo Neruda y Pablo de Rokha seguía con plena vigencia en la poesía chilena, desde un intento reciclador que buscaba un discurso alternativo a las primeras experimentaciones vanguardistas y que quería adaptarse a un repertorio ideológico que había cambiado radicalmente. Una modernidad en crisis, pero articulada en nuevas fórmulas sistémicas, apelaba a sujetos discursivos culturales que recanonizaron viejas formas de la utopía social. La producción de Neruda y de Rokha (me refiero a los "cantos generales" de ambos poetas publicados alrededor de 1950), es un intento de reinstalar al sujeto omnipotente de la modernidad como portavoz del mundo, pero también es una reacción estética frente a un paradigma que se agotaba y cuyos portavoces más representativos volvían a buscar la armonía social y natural con el mundo. En el yo apoteósico de los "cantos", el discurso se

\footnotetext{
Este planteamiento ha sido desarrollado por el autor de este artículo en "La poesía de los cincuenta: aproximaciones a una modernidad en disolución". Taller de Letras 34 (2004); "La poesía de los cincuenta en Chile y España: escorzos y aproximaciones". Mapocho. Revista de Humanidades 60 (2006) y Antología crítica de la poesía chilena. Tomo IV (2006), entre otros trabajos.
} 
devolvía hacia la realidad mitopoética del portavoz de la tribu, del gran vate antiburgués, que se sustentaba en una subjetividad clarividente y mesiánica. Frente a estos intentos de instalación hegemónica y pervivencia residual de los discursos anteriores, emergen tímidamente al comienzo y con cierta fuerza polémica posteriormente algunos textos que pretenden clausurar definitivamente el complejo entramado del imaginario vanguardista, que en el Chile en esos años sobrevivía además en las producciones de poetas vigentes como Humberto Díaz-Casanueva, Rosamel del Valle, Gustavo Ossorio, Omar Cáceres, Eduardo Anguita y los tardíos poemarios del grupo surrealista "La Mandrágora": Teófilo Cid, Braulio Arenas y Enrique Gómez-Correa.

Una promoción de poetas publicitados por el crítico Tomás Lago buscaba revitalizar la tradición popular, devolverle la vida a las palabras y volver a conectarse con el lector ${ }^{2}$. El adalid de este intento fue el antipoeta Nicanor Parra, quien acaba de morir a la edad de 103 años y el cual en 1937, al publicar Cancionero sin nombre (obra que recibió en palabras del propio poeta una manifiesta influencia de Federico García Lorca), echó a andar la poesía de la claridad y la antipoesía. Al respecto, no se puede tampoco desconocer la irrupción innovadora de Violeta Parra, quien hizo la integración entre poesía y canto con una actitud pionera referida a la cultura popular. Una diversidad de líneas poéticas es permeada por la estética antipoética de Parra y el foco artístico se amplía hacia otras tendencias que coinciden con su ruptura. El Larismo (búsqueda del origen y del Lar) en Jorge Teillier, Efraín Barquero, Rolando Cárdenas y Delia Domínguez; la intercalación narrativa y la poesía situada de Enrique Lihn; la resignificación neovanguardista de Gonzalo Rojas y Carlos de Rokha; la militancia urbana de Alfonso Alcalde y Armando Uribe; la crítica de género en Stella Díaz Varín o Irma Astorga y la postura de exploración existencial y popular que problematiza las relaciones campociudad de Miguel Arteche, Alberto Rubio y David Rosenmann-Taub. Estos últimos reasumen las viejas formas métricas, incorporan nuevas temáticas y retornan a las fuentes líricas más elementales (incluyendo la oralidad), de una manera renovada. La segunda mitad del siglo XX será en el plano de las construcciones discursivas de la poesía chilena un terreno multifacético, de

2 Ver al respecto las antologías de Tomás Lago, Ocho nuevos poetas chilenos (1939) y Tres poetas chilenos (1942). 
muchas líneas (convergentes y divergentes) que coexistirán entre sí, pero que también entablarán fuertes querellas generacionales, estéticas y políticas ${ }^{3}$.

\section{EL PROYECTO POÉTICO DE CORTEJO Y EPINICIO}

En 1914, mientras se iniciaba la primera guerra mundial, el poeta chileno Vicente Huidobro publicaba su primer manifiesto "Non Serviam", el que anuncia ya su teoría creacionista, ratificada en "arte poética" de El espejo de agua (1916/18), en que naturaleza y creación se separan. El año del manifiesto es el mismo en que nacía Nicanor Parra, quien mandaría los supuestos huidobrianos al baúl de la tradición con la publicación de Poemas $y$ antipoemas en 1954. Se trata, dirá Parra, de "crear vida en palabras" porque "los poetas bajaron del Olimpo" ("Manifiesto"). Coetáneo en términos literarios del antipoeta, David Rosenmann-Taub publica su primer libro El adolescente en 1941 a los diecisiete años y la primera edición de Cortejo y epinicio en 1949. Autor de más de una docena de textos poéticos, el poeta se aleja de las posturas parrianas, para re-inscribirse en las vanguardias, especialmente en lo que se refiere a la experimentación con el lenguaje (Parra experimenta con las hablas cotidianas, Rosenmann-Taub intercala cultismos, anacronismos y neologismos en un despliegue casi culterano) y a cierto redescubrimiento del mundo natural desde una perspectiva pictórica y musical. En este sentido, a veces hay un fuerte trabajo intertextual con algunos textos de Gabriela Mistral, una comunión de rango existencial con César Vallejo y un sentido de trascendencia casi mística que rememora a San Juan de la $\mathrm{Cruz}^{4}$. Sin embargo, su producción poética se focaliza más en la multiplicación y ensanchamiento de las sensaciones que provoca su punzante dispositivo verbal, que roe y corroe las palabras hasta estrujarlas, darlas vuelta y diseminar su vasta gama de sentidos. En el mismo tenor, se

\footnotetext{
Al respecto, ver el Tomo IV de mi Antología crítica de la poesía chilena (2006), ya citado.

Me refiero especialmente a lo que se ha denominado el "macabrismo" mistraliano analizado especialmente por Grínor Rojo en Dirán que está en la gloria (1997) y por Jorge Guzmán en Diferencias latinoamericanas (1986); en el caso de Vallejo, a los análisis de Saúl Yurkievich, esencialmente en Fundadores de la poesía latinoamericana (1984) y a San Juan de la Cruz en su búsqueda de una trascendencia espiritual en su obra Cántico espiritual, sobre la cual el propio poeta se ha expresado en entrevistas.
} 
plantea la antítesis representada por el vaivén retórico que va de la extrañeza que provoca un discurso siempre novedoso y lejano, a la cotidianidad de una emocionalidad que busca a tientas un asidero en lo real-natural para enfrentar a la muerte.

Con respecto a la tetralogía CORTEJO Y EPINICIO, se hace necesario dar una corta explicación. Se compone de Cortejo y epinicio I (cuya primera edición se publicó en 1949, la segunda en 1978/ 2002 y la última en el 2013 con el título de El zócalo); Cortejo y epinicio II (con el título de El mensajero: 2003); Cortejo y epinicio III (con el título de La opción: 2011) y Cortejo y epinicio IV (con el título de La noche antes: 2013). En la edición de El zócalo, el primer libro de la tetralogía, hicimos una aclaración preliminar (con la ayuda del autor), que intentaba dar cuenta de la posible confusión de libros, fechas, precedentes y la secuencia que la tetralogía tiene actualmente. En síntesis, esa aclaración señalaba lo que sigue. Dentro de la trayectoria poética de Rosenmann-Taub, la tetralogía es una obra que el poeta ha escrito a lo largo de su vida. El primer libro publicado en 1949, Cortejo y epinicio, tomó el nombre de toda la tetralogía. Al concebir la tetralogía, el poeta denominó El zócalo al primer volumen y a la tetralogía completa con el nombre de CORTEJO Y EPINICIO. La razón de llamar Cortejo y epinicio al primer libro se debió a una sugerencia del editor de ese entonces para dar a conocer al poeta. Por el reconocimiento de público que posteriormente tuvo el libro, se mantuvo el título inicial en las siguientes ediciones, pero ahora que la tetralogía está completa se ha restituido el nombre original de ese libro. Acerca del significado del título CORTEJO Y EPINICIO que llevan los cuatro tomos, adelantamos una hipótesis que se difumina con la del poeta. CORTEJO: el poeta corteja la realidad para que se abra ante él. Procesión de elementos análogos de la naturaleza y del ser humano, como desfile. Cortejo de bodas con la realidad. Cortejo como funeral: homenaje a la condición de existir, que implica desaparecer. EPINICIO: la victoria de asumir este fracaso final. También ambos conceptos se piensan como verbos: yo cortejo, yo asedio por un lado y yo epinicio, yo canto victoria, por otro. Así, CORTEJO Y EPINICIO son lo que es para el ser humano vivir en la tierra en un particular tiempo y espacio desde su ahora hasta su adiós. Resistir a la naturaleza es ya un triunfo. De algún modo, toda la obra del autor representa esta resistencia a la temporalidad humana y al asedio del mundo natural.

Por último indicar que el volumen I (El zócalo) presenta la primavera, la mañana, los primeros veinte años; el volumen II (El mensajero) implica el verano, la tarde, de los veinte años a los cuarenta; el volumen III (La opción) 
representa el otoño, el crepúsculo, de los cuarenta a los sesenta años, y el volumen IV (la noche antes), el invierno, la noche, después de los sesenta años. En síntesis, el nacimiento y la agonía, el amanecer y la oscuridad, el triunfo de una derrota: un epinicio. El resto es trabajo del lector ${ }^{5}$.

Los críticos se han acercado de distintas maneras a las relaciones que la poesía de Rosenmann-Taub sostiene con una búsqueda de la trascendencia hacia el origen y la muerte (pasado y futuro). Jaime Concha alude a la aspiración de volver a habitar el mundo que se dejó después de la muerte y a la férrea articulación que se produce entre el nacer y el morir, entre la fertilidad y la destrucción, lo que se traduce en el "éxtasis de la muerte" en los poemas (2008:1-18). Sabrina Constanzo relaciona el tema con una incursión en el conocimiento, que ausculta el sentido de la existencia humana y en la muerte como acceso a otra realidad (2012: 85-94). Para Juanita Cifuentes, el viaje a la memoria es un viaje que intenta abolir las fronteras del tiempo y presentizar el origen para exorcizar a la muerte (2012: 95-110). Teodosio Fernández inscribe esta problemática dentro de un proceso postvanguardista en que se recuperan los sentimientos, al mismo tiempo que se experimenta una sensación constante de pérdida o imposibilidad (2012: 111-124). Álvaro Salvador y Erika Martínez escriben sobre el regreso al origen a través de la muerte, lo que sería un auténtico comienzo, al mismo tiempo que la vinculación con la naturaleza produce una presentización de la exaltación vital (2010: 7-26). Jorge Monteleone alude también a esta muerte, que no es solo el final sino también el origen y agrega que se trata de una poesía que se sostiene entre dualidades y que adquiere el carácter de una mística negativa (2012: 7-31). El autor de este trabajo ha intentado incursionar desde diferentes perspectivas en esta línea matricial del poeta, especialmente en el tópico del retorno a la fuente como trascendencia (2011: 172-188 y 2012: 13-32). Por lo tanto, aquí seguimos un camino trazado con anterioridad.

\footnotetext{
Esta aclaración ya la hicimos en los "preliminares" de la edición de El zócalo en el año 2013, a partir de una anotación del propio David Rosenmann-Taub. Una explicación parecida aparece en El duelo de la luz (Antología de Cortejo y epinicio) de David RosenmannTaub, publicada por Alvaro Salvador y Erika Martínez en España (2014). El título de este libro está tomado del poema "Ficción" del tomo II que dice: "El duelo de la luz: la luz del sueño/ el sueño de la luz: la luz del duelo..." (22).
} 


\section{EL ZÓCALO: FUENTE Y MATRIZ}

El zócalo (Cortejo y epinicio I: 2013) difiere de la primera edición de 1949 en aspectos que si bien no cambian lo esencial, reducen, podan y comprimen los textos, borrando partes, eliminando versos y secuencias, trabajando de una manera más densa las elipsis y los efectos de discontinuidad. Mientras la versión de 1949 relevaba la métrica, el ritmo tradicional, la emocionalidad (uso del endecasílabo, del dodecasílabo, del alejandrino, del soneto, de los apóstrofes, repeticiones, anáforas, onomatopeyas), el nuevo texto tiene un ritmo más interno, se desboca de la métrica, pule las palabras y las frases hasta el paroxismo, se impregna de neologismos, produciendo por contraste un movimiento asimétrico hacia una musicalidad atonal armónica con la escritura. En sintonía con Octavio $\mathrm{Paz}^{6}$, se podría decir que la primera versión es más analógica con una estética neorromántica y modernista, mientras que la segunda retoma el carácter experimental de las vanguardias, sin dejar de distanciarse de ellas a través de la ironía, del cuestionamiento del sujeto en su relación con el mundo y de una reescritura casi obsesiva, que agudiza el significado hasta volverlo semiopaco o totalmente transparente: en este último sentido hablamos de una poesía neovanguardista. Esta misma contraposición se presenta a veces entre la rigurosidad sintética de algunos poemas, como por ejemplo el poema "Sazón”, compuesto de cuatro palabras: "Níspero ¡Quién! Intrusos. . Trasnochamos". (107); en contraste con otras donde se trata de la irrupción de un sujeto que se desborda en imprecaciones y apelaciones apostróficas, como en "Diálogo sepulcral" del mismo libro: "Y me imprecaste en medio de la sala:/'Te sacudí la vida y no morías,/te ceñí con mi absorta gangrena y no morías" (25). En este primer tomo, el intencionado alejamiento del poeta de la lengua común va acompañado de una intercalación constante de formas coloquiales, campesinas y populares, que se combinan con los neologismos para entregar al lector una ilusión de cercanía con la oralidad, que lo vincula con otros/as poetas coetáneos de América Latina: pensemos además de los chilenos Parra, Gonzalo Rojas, Enrique Lihn, Delia Domínguez o Alfonso Alcalde, en Ernesto Cardenal, Efraín Huerta, Juan Gelman, Idea Vilariño, Heberto Padilla o Carlos Germán Belli.

$6 \quad$ El análisis de esta temática puede leerse en Los hijos del limo. Del romanticismo a la vanguardia (1974 y 1987) de Octavio Paz, específicamente en el capítulo "Analogía e ironía". 
Si CORTEJO Y EPINICIO, de acuerdo con los sentidos que hemos enunciado, muestra las dos caras de la vida humana, la precaria victoria y la desaparición, el himno triunfal y el cortejo de la muerte, El zócalo se instala como el basamento de la vida humana. Es por ello que el Tomo I representa, a nuestro juicio, la matriz desde la cual se desarrolla todo el "multiverso" de Rosenmann-Taub y por lo tanto es el "basamento" de nuestro análisis. Así, el poema I, que conforma el preludio del libro, es también el "Preludio" de una etapa de la vida que inicia el periplo del sujeto y del poeta. El libro se cierra con el poema LXXX, que originalmente llevaba el título "De la tierra y el hombre", en el cual la tierra aparece revitalizada con los huesos de los muertos (p. 137). Entre el primero y el último poema se desarrolla el movimiento del sujeto hacia la vida, su aspiración a la regeneración y a encauzar la muerte hacia un origen innombrable. Citamos in extenso el poema I escrito en cursivas, por la importancia que tiene como pórtico de toda la tetralogía:

Después, después el viento entre dos cimas,

y el hermano alacrán que se encabrita,

y las mareas rojas sobre el día.

Voraz volcán: aureola sin imperio.

El buitre morirá: laxo castigo.

Después, después el himno entre dos víboras.

Después la noche que no conocemos

y extendido en lo nunca un solo cuerpo

callado como luz. Después el viento (5).

Este preludio sintetiza el tópico que hemos anunciado: movimiento que va desde la vida hacia la muerte y la regeneración que sucede a esta muerte a partir de la repetición en el poema del "después”, expresión que intensifica el movimiento que imbrica la vida-muerte-vida en dos tríadas: en la primera, donde la vida animada y lo natural (viento, alacrán, marea, volcán, buitre) se mueve hacia un futuro incierto; y en la segunda, donde el cronotopo del "futuro" se extiende y amplía hacia un absoluto que unifica noche y luz: "extendido en lo nunca un solo cuerpo /callado como luz": muerte noche y muerte luz. El preludio ejerce el sentido de una entrada en un tiempo-lugar que se sitúa en un después, un universo que se muestra a través de imágenes desorbitadas que evocan la muerte, a partir de un desplazamiento permanente: "después el viento...las mareas rojas...el buitre...después, el grito entre dos víboras...la noche que no conocemos...después el viento". A partir de esta extensión en el espacio, que lo es en el tiempo, se nos sumerge en un 
mundo siempre desplazado en el "después", en el "nunca", el "vacío" y el "entre", unión con una posible trascendencia que va del movimiento a la inmovilidad: "el viento entre dos cimas". Es por ese lugar del "nunca" y del "después", que se desarrolla el despliegue de la memoria en el poemario con sus movimientos hacia un pasado que solo relumbra en ese no-lugar entre la vida y la muerte, pero también en un "entre" después de la muerte. Como ya indicamos, el círculo se cierra con el poema final del libro también en cursivas. Dice el poema: "Agua de tierra y sal de tierra me penetran ...Crea la tierra/ alas:/ crea tierra...y es la tierra de tierra,/y es el éter de tierra... tierra y alma, en la luz se precipitan" (137-138). Todo se hace tierra, la que hace germinar de nuevo la vida y se alimenta de los cuerpos que caen. Los cuerpos caen y mueren, pero todo cae y muere y a la vez brota de la tierra: "sobre la cumbre, muere, muñón de tierra, el aire./Vedada epifanía hacia los cielos, / mueren mis brazos./ Muero...Se precipita el llanto./ La tierra se endereza: la hornagueo./Y los bramidos de la tierra, sangre" (138). La tierra se humaniza, como en otros textos de Rosenmann-Taub y se transforma en un bálsamo a través de su llanto ${ }^{7}$. La tierra se transforma en la madre que hace dormir y nos hace navegar hacia la paz: "Hay que dormir el sueño de la tierra./ Hay que dormir./ Dormir./ Apresar la cascada./ Y en la sola mejilla de la tierra/apoyar las mejillas,/navegando a la paz" (Ibid). De este modo, en el texto final, Cortejo y Epinicio se reúnen. El dormido junta huesos y sueños, se hace uno con la tierra transformadora: "No ha de cesar el tiempo su pasión. No sabrél si hueso o tierra lo que roza el sueño" (139).Vida y muerte, aparecer y desaparecer, como amanecer y noche, como aire y tierra, se funden y fragmentan en una unión-desunión permanente que reaparece en el sueño como un fulgor de trascendencia.

\section{LA TETRALOGÍA}

La tetralogía de David Rosenmann-Taub como el Cuarteto de Alejandría de Lawrence Durrell ${ }^{8}$, busca replicar las experiencias del sujeto de cada uno

\footnotetext{
Por ejemplo, “¡Boscaje! ¡Piedra, el éter y la piedra sólo atina a gemir!” en El mensajero (68); "Cómo me gustaría ser esa oscura ciénaga/ solo bajo la lluvia", Ibid (92); "Yo: un sendero/ Tú: la tierra", Ibidem (111).

8 Nos referimos a la tetralogía de Lawrence Durrell, El cuarteto de Alejandría (19571960), donde cada personaje asume la misma historia contada desde diferentes vertientes
} 
de los textos en los otros. Se trata de establecer la transitoriedad del instante humano en la permanencia de una trascendencia que se vacía permanentemente en la medida en que la experiencia se desfonda y deja lugar al dolor, a la desesperación o a la muerte. Este tránsito existencial que permea a toda la neovanguardia se da no solo a través de las significaciones ínsitas en los textos, sino también en el proyecto mismo de la escritura. La experiencia del autor instalada en cada uno de los libros remite a las partes y al contenido de los otros. Las distintas etapas de la vida que representa cada uno de los textos (juventud, adultez, madurez y vejez), se espejean unas a otras, conforman un "multiverso" reflectante, como ha señalado el propio poeta en diversas entrevistas: "el poeta: la voz del Multiverso". Lo aclara Jorge Monteleone en el prólogo a la antología Multiverso (2012) publicada en Buenos Aires: “...aquello que nombra el poema no es el Universo, sino ese espacio-tiempo indecidible, la intersección entre el ser y el no-ser, entre la vida y la muerte, entre lo visible y lo invisible, lo externo y lo interno, el sueño y la vigilia: ese lugar, ese topos, es el Multiverso" (17). Espacio múltiple que también es tiempo multiplicado, cronotopo que se trasciende hacia atrás y hacia adelante, desde un presente efímero pero necesario para la escritura. Hay secciones que se reiteran con ligeras variaciones, otras que se transforman porque varía la perspectiva del sujeto y otras que, por último, se ocultan bajo encabezados analógicos que dan cuenta de los mismos significados con otros nombres. Como ejemplo podemos mencionar que los títulos de las secciones "Recreos" y "Fortaleza" que aparecen en el libro I de la versión más actual (El zócalo), se repiten en el libro II (El mensajero) y el IV (La noche antes); así mismo la sección "Continuo éxtasis" del tomo I es también título en el tomo III ( $L a$ opción) y el IV y la sección "Sarcasmo" del Tomo I se repite en el III y el IV. La intrincada operación de entrecruce de cada una de estas secciones en los diversos tomos de la tetralogía se expresa en conformaciones textuales que se unifican o separan de acuerdo a ciertas categorías espaciales, temporales, sensoriales, afectivas, plásticas, contextuales, diacrónicas o sincrónicas que el sujeto o los sujetos de los poemas operacionalizan y que probablemente darían para una interpretación más exhaustiva. La tetralogía es un juego de espejos cóncavos y convexos que aluden permanentemente a convertir las

significativas, pero también desde distintas visiones de mundo. La obra incursiona en las diversas versiones de los mismos hechos, al estilo de las películas Stagecoach (1939) de John Ford y Los siete samurais (1954) de Akira Kurosawa, films que experimentan con el punto de vista. 
representaciones que se dan de forma sintagmática en paradigma: aspiración a unificar una realidad que se presenta de manera continua y segmentada, temporal y espacialmente. El juego altamente complejo de la escritura del poeta invita a realizar lecturas que trascienden este artículo, el cual se focaliza en la problematización enunciada.

\section{ORIGEN, MUERTE Y REGENERACIÓN}

En esta sección, hacemos referencia a una serie de poemas que desde el tomo I despliegan el deseo de devolver al sujeto a la unidad original, así como su aspiración a una regeneración que se produce en un país más allá de la vida y de la muerte, con estrategias variadas y diferencias discursivas.

Una variante que aparece en varios poemas de El zócalo es el surgimiento de la muerte desde la infancia y la obsesión permanente del sujeto de retornar a su origen terrestre, tal como notamos en el texto que sirve de colofón al libro y que ya citamos (LXXX). Esto mismo se aprecia en el poema VII "Aerolito" de la sección Esfera, donde leemos: "Desde la edad de las perlas limpias,/ cuando no había ninfas viejas,/ sólo niñas./ Ibas corriendo hacia la muerte/ sin tu relámpago en las bridas" (33). Como comentario habría que agregar que este poema se titulaba originalmente "Moi vivant" en la edición de 1949 y alude a que la existencia humana inicia su desgaste y degradación desde su origen. Otros elementos del tomo I intensifican las metáforas de la devastación del tiempo: cizaña, exequias, astillas, granizal, ojeras, legaña, ranciedad, roña, murciélagos, devastación que se inicia en "la edad de las perlas limpias", pero "sin tu relámpago en las bridas" (VII: 17). El ritornello que se repite con variantes va anunciando en sus cambios la transformación del punto de vista del sujeto, quien va graduando su perspectiva que se hace cada vez más oscura y deteriorada: "Era la edad de las segundillas...Era la edad de las roñas limpias..." (17-19); hasta el presente donde el anuncio de la muerte es inminente a través de las imágenes del granizal, las exequias, las hachas y las astillas : ¿Devastas, granizal,/ mis perennes exequias?/ La muerte sorda.../Hachas y astillas/ rechazan pomos y brebajes" (19). En El mensajero (Tomo II) también la presencia de la muerte está presente como prefiguración del futuro. El título de la primera sección Vitamortis señala lo indisoluble que es para el autor la relación entre la vida y la muerte. Los poemas intensifican el temple de ánimo ominoso: en el poema I se lee: "Vacante /rectitud./ Transitoria, mi carne/ finará más aún" (11). Y en el II titulado "La 
cita", leemos: "Preguntarán en casa/ por mí. ¡Tanto feriado sin tu zarpa!/ Sepelio, ¿no me amas?" (12). El IV que lleva el título de "Conjuro" reitera la misma representación a través del descenso del sujeto: “¡Desciende!: los riscos anuncian la noche, /las lágrimas curten sabor de crepúsculo...¡Desciende!: los niños restauran agüeros... iDesciende!: las púas del humo, las fundas/ labriegas de ruines mazorcas,/ te llaman, te estrujan...almohádame y mádreme y créceme./ Oh blanca tiniebla de fijeza viva./ 'Desciéndeme, Nieve!' (14). Poema éste donde la intensificación del sentimiento de caída se aúna con el delirante deseo de volver al origen en una especie de escenario mortuorio pero también trascendente. En otros poemas del tomo II, la trascendencia mortuoria alcanza todo el mundo que rodea la conciencia de lo humano, como son los objetos inanimados (utensilios, muebles, objetos mecánicos). Ocurre por ejemplo con el poema VIII ("Estertor") donde "Diván travieso respiras varillas", "Deliras:/ diván" y "Respiras,/ callada maestranza./ ¿Callada?" (19) o en el poema IX ("Las once") donde los alimentos se antropomorfizan adquiriendo dimensiones temporales: "Ese queso perturba su cadáver en la alcachofa, cárdeno, a la izquierda", Prendedor de humedades/ hiede el pan" o "En sus nichos, / confusas compoteras" (20). Lo mismo ocurre en el poema XX donde "La lejía y la esponja de alambreorgullo / han tolerado, a saltos, su escoria histérica; / los platos, satisfechos, bajo la mesa,/ han pulido un lozano chillido puro; (33)". Hacer de lo inanimado algo sensible parece ser para la poesía de Rosenmann-Taub una manera de combatir la inhumanidad que percibe en los seres humanos de nuestro tiempo y a la vez una manera de exorcizar la transitoriedad de nuestro presente. Así, "el muro ...late plácidamente...los rosales otean los caminos...las tejas cuchichean" (XXIII:36); "el sol pica la espuela:...El henar y la tierra adeudan cueca...la siesta de copihues...¿Y el horizonte? Con olor a mote" (XXVIII: 41) o de un modo más lúdico en el poema LV: "Las margaritas se emperejilan:/ unas a otras,/ ¡hábrase visto!:/ supremas duelas del aroma; / los nimbos, predio,/ y el predio, nimbos...¡Nidos, bullidme glaucopajizo!/ ¡Maizales cercos!/ ¡Untos sandiales!” (77-78).

La repetición de estas representaciones de lo no humano pero humanizado se reitera a través de todo el tomo II, explotando de una manera distinta en el poema LXIII, donde se produce una inversión fundamental. El poema escrito excepcionalmente en alejandrinos se compone de 12 estrofas de las cuales hay ocho de tres versos y tres de cuatro versos, todas con estructura paralelística y construcción anafórica, lo que permite acentuar su forma de conjuro. El Leitmotiv reiterativo anuncia este deseo de muerte que ha permeado otros 
poemas de la tetralogía, pero vinculado a una trascendencia vacía que nos recuerda en cierto modo la estética vallejiana donde el ser humano dolorido y degradado lleva al paroxismo su orfandad y su deseo de disolverse en la naturaleza ${ }^{9}$. Así es como los objetos se humanizan y los seres humanos se animalizan o se mineralizan. Dice el sujeto del poema en el conjuro rector: "Cómo me gustaría ser esa oscura ciénaga, /libre de lo de ayer, qué alivio, oscura ciénaga,/ dejar correr el tiempo. ¡La más oscura ciénaga!” (91). El "cómo me gustaría" se reproduce a través de 7 de las estrofas del poema con un tono ensalmático y encantatorio, cuya predicación confirma la contradicción del sujeto deseante que se proyecta hacia "la oscura ciénaga", epítome de su nadificación disolutoria. El deseo de borrarse del mundo lleva al sujeto a una aspiración distópica que se intensifica cada vez más: "jamás haber nacido", "lograr morirme ahora", "rodar por el vacío", "ser el cero del polvo", "para no volver nunca", "mi muerte la causa de mi vida", para finalmente apelar sintéticamente a la realidad de una divinidad en la que se desea creer, solo para que pueda borrarlo de la memoria y hacerlo desaparecer: "Dios mío, yo creyera en Ti para no ser.../Cómo me gustaría olvidarte, Dios mío. /Cavílame en tu nada. ¡No me hagas volver nunca!” (92). A nuestro juicio, la figura de Dios aparece aquí como un pretexto del poeta-sujeto para reiterar su deseo de muerte y su aspiración a una regeneración que se congela en la trascendencia vacua (de barro, tierra y agua: la ciénaga), deseo de nada o símbolo de la impotencia humana ${ }^{10}$. Este deseo de muerte se replica en poemas del Tomo III (La opción) y el Tomo IV (La noche antes). En el III, especialmente en el poema XIV titulado "La traición", que citamos ampliamente, porque con claridad se percibe esta intencionalidad del sujeto por volver a un origen imposible:

9 Dirá el poema V del Tomo III: "hasta de mi orfandad desarraigado,/ ampare el sopetón de lo extraviado" (17).

10 En una entrevista, el autor señalaba: "Para mí, el término Dios es terrenal. Lo que llamo divino es la experiencia terrenal absoluta. No tiene nada que ver con el concepto de las religiones, en donde no hallo ninguna divina divinidad" (El Mercurio, Revista de Libros, 2002: 7). Idea que reitera en el año 2005: "Mi obra no tiene nada que ver con el esoterismo. Para mí, Dios no es fenómeno religioso, ni siquiera lo asocio a la religión. Cuando me refiero a árboles, no hago botánica" (El Mercurio, Artes y Letras: E 5). 
Me voy como no fui, como no iría... Yendo desde el faro del Vuélvete al cráter del Nosigas (...) me fui como no voy, como no iría... Yendo desde el Ser a la Ráfaga, me omití, me desdije:

(...) ¿Qué voz de retroceso

me amelga, me arremanga, me difiere, me zanja, me coarta, me escupe, me preserva, me franja, me sentencia al absceso

que me desextasia, vendiéndome, ladino, a la sofocación del Problema divino? (...)

Corrí hacia mis perdido padres: en el umbral me esperaban: sollozos

(...) Me tendieron sus pobres brazos fieles. Sus pupilas: opacos cascabeles. Les aullé.

“¡He vuelto! ¡He vuelto! ¡He vuelto!” Y era la despedida. (26-27)

Del Tomo IV, citamos dos ejemplos ya bajo el símbolo de la representación de la vejez. En el primero el ritornello del refrán anuncia lo inevitable: "Arrebujarse. No hay más/ que sentir frío: morir./ Sucumbiendo, resistir/la nostalgia del jamás./Arrebujarse. No hay más/ que sentir frío: morir” (XII: 23).

En el segundo, traspasar el umbral y cortejar a la muerte vuelven a ser el centro de la búsqueda poética:

Es la hora en que extiendo a los míos a mi lado...

Entrecierro los párpados:

el río de los míos se desliza en mis venas $(\ldots)$

el dosel en que hiedo, la sal en que sudario, el hisopo en que nunca, la hendedura en que niño... y me brinco, me azoto, me espejo, me apalanco... es la hora en que llamo los míos a mi lado, es la hora en que hondeo la nada entre mis dedos, la hora en que suplico, la victoria en que oficio, la serpiente en que vibro, la sombra en que penetro. (XIII: 26-28)

Síntesis de la contradicción entre el deseo de un sujeto de querer borrarse en el silencio, de querer integrarse a una totalidad natural o divina, o de hacerse acontecimiento de sí mismo en la escritura a través de una aguda autoconciencia de su intento de trascendencia hacia una suprarrealidad que lo supera. 


\section{Y FINAL: “ACABO DE MORIR... SOY UN RECIÉN NACIDO”}

El símbolo de la vejez, el deterioro y la muerte ínsita desde el origen se expande como una problemática por toda la tetralogía, que se inicia en el primer tomo con la infancia del sujeto poético (la mañana) y termina en el cuarto tomo con su vejez (la noche), pasando por los cuatro estadios de la naturaleza: primavera, verano, otoño e invierno, y donde poemas, estaciones y edades se interpenetran, integran y separan. Un poema del Tomo I que resume esta idea de una manera sintética es el poema "Genetrix" de solo dos versos: "Acabo de morir: para la tierra/ soy un recién nacido" (30). Este dialoga con el poema VII del Tomo IV, donde se lee: "mi primera/carcajada en la tierra,/ con más fiera agonía/ de fiera pesadumbre,/ que mi primer vagido" (18). En "Canción de cuna" (Tomo I), poema que hemos analizado en otro artículo ${ }^{11}$, la canción de cuna se hace mortuoria, provocando el efecto antitético de representar la muerte del infante desde su origen: "Con retales de musgo, cariño mío,/ te envolveré. Haga tuto mi niño lindo.../ En tus manos, goloso cariño mío,/ mil gusanos bonitos./ Haga tuto mi niño, niño podrido"(23). La exhortación del sujeto es cada vez más apremiante y contradictoria; lo que parece ser un ofrecimiento de vida se hace un ofrecimiento de muerte: envolver con retazos de musgo, entregar para jugar o comer gusanos podridos e incitar al sueño al niño podrido, son elementos que apuntan a devolver al niño a la tierra, integrándolo a su ámbito ancestral. En la medida en que trascurre el poema, el deseo filial del sujeto que presagia la muerte intenta exorcizarla con la canción de cuna, reinstalándola como parte de la vida y por lo tanto, también como una posible regeneración natural. De esta manera, la relación entre muerte y sueño se hace cada vez más patente hasta convertirse en el poema en un proceso de transformación del infante, que lo une de nuevo a la vida a través de la tierra: "Muy luego con babero de barro:/ niño violáceo... Ciérrense tus ojitos, mi lucerito./Ciérralos para siempre, niño podrido (... Aliento mío, aliento mío.)/ Con pañales de hormigas, cariño mío,/ te abrigaré el potito./ Duérmete para siempre mi niño lindo" (39). El contraste entre el tono dulcificado de la canción admonitoria (cuídate, aliento mío, niño lindo)

$11 \quad \mathrm{Al}$ respecto, ver el capítulo "Cortejo y Epinicio de David Rosenmann-Taub: exorcismos de la memoria" en el libro Lo singular y lo universal en la poesía de David Rosenmann-Taub (2012: 13-32). 
y las imágenes macabras y mortuorias del poema aluden más a un ritual de pasaje o un umbral simbólico que a una canción dolorida o triste.

Otros poemas de El zócalo que claramente aluden a este deseo de regeneración más allá de la muerte (además del ya citado "Genetrix") son "Retrospectiva" y los textos "LVII" y "LXVI". En "Retrospectiva", la memoria adopta la imagen del armario para emprender un viaje hacia el pasado que busca detener la huida de la vida hacia la muerte. Así, el yo describe su itinerario hacia los recuerdos de infancia ("mi alma está de viaje", 113) como un rito de despedida ("brinca mi despedida", 113) haciendo un recuento de situaciones, lugares y objetos que llenan su armario-memoria: "bizcochos y madre", "colección de súplicas", "trompo sentencioso", "calcomanías", "seria caja de zapatos", "canicas, volantines", "el emboque", "fogones de visires y príncipes", etc. Frente a este recuento de la vida pretérita, el sujeto reconoce que "mi cuerpo es un celaje que se aleja y no acierta/ a detener la huida" (114). De nuevo, como en otros poemas, hay un gesto exorcizante que busca detener esta huida hacia la muerte, al afincarse en la memoria-armario: "Yo, yo, adorado cauce, quédate en su santuario,/ revolotea estático en el beleño armario" (114). De esta manera, se contrapone el "cauce-rio" que corre hacia la muerte con el armario del recuerdo que congela la vida en la memoria y que induce a viajar hacia atrás, para exorcizar lo inevitable del morir en el viaje hacia adelante. Lo mismo ocurrirá con el poema LVII, un soneto donde el sujeto describe en ambos cuartetos la recordada cocina de su infancia, reviviendo los objetos ("la taza de café, la cafetera... la obediente sartén... la mostaza, la nevera... el roto lavaplatos... la sopera pimpante"), pero también rememorando olores, sabores, colores, visiones ("el vapor que mitiga mi esqueleto... el parapeto de vainilla, azafrán y primavera"), con el fin de volver a un origen que vivifica el presente como "lugar de integridades" (117); para finalmente abrirse a un futuro de "tiempo sin tiempo", aunque también regenerativo. Esta definición se hace posible a través de un retorno a esa imagen integral en los tercetos del soneto, los que definen magistralmente el destino de unir muerte con naturaleza y reino humano: "cuando muera/ y mi tiempo -sin tiempo-vibra y crezca,/ en ronroneo fiel todo lo mío/claro retorne a tu silvestre estera/ y tu vapor -sin fin- lo desvanezca" (117).

Un último ejemplo de este tópico lo mostramos en el poema LXVI, donde el sujeto inicia la búsqueda de esa infancia que se quiere recobrara través de la incursión en el cuarto de la hermana Sara que ya no está, no sabemos si muerta o solo ausente ("me he sumergido en el cuarto de Sara", 127). Como en el texto anterior, la incursión bucea entre los objetos para reencontrarse con 
los recuerdos: olores, sabores, imágenes ("hurgando una quimera de pudores y almizcles / en las gavetas donde ya no hay nada:/ embriaguez de baldosa con lluvia, / de retratos o broches o acacias", 127). Esta enumeración caótica se amplía con objetos y utensilios de toda laya, a partir de cuya descripción se ahonda en el sentimiento de vacío y de abandono del sujeto: "Tras mascar el ropero vacío,/ rasguñando el rincón de la lámpara,/ he lamido tapiz y paredes.../ he gritado, vicioso, por la rambla/ de la victrola desaparecida.../ para arribar al nácar de la infancia" (127). En este poema, si bien la búsqueda no culmina en ninguna trascendencia, da cuenta de la necesidad que tiene el sujeto de hacer presente lo que ya no está, como una manera de recobrar su propia identidad: "Arderme, persistirme.../tan mendigo, tan dentro/me buscaba y jadeaba y buscaba" (128).

Existe otra variante de este deseo de trascendencia y regeneración, que se da a través de la resistencia de la vida humana frente a la muerte, tópico que se expresa de muchas maneras. Por ejemplo, como un necesario deseo de sobrevivencia de un sujeto que se instala frente a la muerte y la apostrofa a sabiendas del poder que tiene sobre la vida. En el inicio del poema XIII, "Diálogo sepulcral", leemos: "Y me imprecaste en medio de la sala:/ 'Te sacudí la vida y no morías; te ceñí con mi absorta gangrena y no morías'. 'Ven' -repliqué...' ¿carcelero!...Empújame a tu apremio: me reconquistarás...'”(41). Al llamado de la muerte, el sujeto responde con su historia personal de enfrentamientos pasados y de sobrevivencias. El diálogo sepulcral culmina con la representación final de la vida como agonía, pero también como continuidad: "tu mirada bordó fénix guirnalda/ que anudó las cortinas y trizó las ventanas./Dentro de ti, por fin, agonicé” (41). En otra instancia, el deseo de muerte se integra con el deseo de renovación en la naturaleza, como ocurre en el poema XXV: "Inúndame: la fosa persevera sedienta./ Desátame: mis brazos no son sino semillas" (59). Hay textos donde la aspiración trascendente del sujeto solo encuentra el vacío y por lo tanto lo único que permanece es el deseo, pero casi siempre inútil, como en el poema XXVIII, "Oda heroica”: “¡Qué estuoso cáliz ebrio, qué resplandor de hoguera/ nos une desuniéndonos como a dos llamas tercas!.../queriendo ser planetas./ ¡Qué compás miserable, qué resplandor de hoguera!” (66). Lo mismo ocurre en el poema XXXV, donde el sujeto se identifica con la decrepitud y la podredumbre y desarrolla una posible trascendencia vacua a partir de la metonimia del "escupo negro", que en el poema LXIII se hermana con la imagen de "la oscura ciénaga": "soy en mi sueño un denso escupo negro/ de la acera insondable, cual ponzoña/ u ojo aborrecido, desertor:/ 
un denso escupo negro,/ taciturno, en la orina legamosa,/ rutilando, en la sombra, más que el sol" (77). Aquí el deseo de trascendencia y el deseo de muerte se aúnan en un sujeto agónico que se identifica con el dolor de existir a partir de la conciencia de la memoria y de la proyección. El propio poeta ha ratificado este sentimiento de habitar un presente fugaz y momentáneo:

He escrito y escribo para ayer y mañana, pensando en nutrir a los que se fueron y a los que vendrán. El presente es el lugar en donde me instalo a escribir en dirección al pasado y al futuro. Desde el punto de vista del pensamiento, el presente es el tiempo menos real. Desde el punto de vista de la inspiración, sí, es el único factor que me mueve: estoy vivo (Entrevista 2002: 6).

\section{COLOFÓN}

A través de algunos poemas de la tetralogía CORTEJO Y EPINICIO hemos querido mostrar uno de los tópicos fundamentales de la obra de David Rosenmann-Taub, cual es la representación de una aspiración hacia una trascendencia que busca superar la finitud humana, lo que solo se produce a través de la memoria del origen, que nos devuelve el vínculo ancestral y esencial con la naturaleza y/o a una búsqueda mística que quiere reencontrarse con una divinidad ausente. De este modo, los textos poéticos pasan a ser el soporte corporal del anhelo de integrarse con una entidad totalizadora natural o divina, fuente de renovación o redención (como han señalado Salvador y Martínez), como el deseo de borrarse en el silencio (Monteleone), o finalmente como acontecimiento del sí mismo en la escritura a través de una aguda autoconciencia del propio intento de conocimiento o de verdad. Todo ello vinculado a una aspiración trascendente que opera desde el Romanticismo en la poesía occidental, pero que se desdibuja o se vuelve sobre el sujeto con las vanguardias, para culminar en estos versos con el deseo de la nada o la reintegración en la naturaleza (una oscura ciénaga, un escupo negro), como única finalidad de un sujeto que en el proceso moderno ha llegado a su total desintegración o disolución. Así, el sujeto rosenmanntiano se devuelve no solo sobre sus propias huellas personales (infancia, origen, padres) sino también sobre las huellas de una tradición poética que busca en el canto su sobrevivencia, sabiendo de antemano que frente a los límites de la existencia, lo único que queda es volver una y otra vez a memorizar lo andado y a proyectar lo soñado. Como ha señalado el mismo poeta: "Yo 
canto como el sol, y el sol no canta. Yo sueño como Dios y Dios no sueña. Yo cual la tierra, muero, y la tierra no muere: ipero canta!" (Cuaderno de poesía, "El raudal", Poema IV).

\section{BIBLIOGRAFÍA}

Berger, Beatríz. "Todo poema en mí, tiene su partitura”. Entrevista a David Rosenmann-Taub en Revista de Libros, El Mercurio (6 de julio de 2002): 6-8.

Cifuentes-Louault, Juanita. "Componer, descomponer y recomponer la memoria: una lectura de País más allá de David Rosenmann-Taub”. Lo singular y lo universal en la poesía de David Rosenmann-Taub. México/París: RILMA 2/ ADEHL (2012): 95-110.

Concha, Jaime. "Nace una singularidad: el primer libro de David Rosenmann-Taub". Revista Iberoamericana 224 (2008): 1-18.

Constanzo, Sabrina. "De lo personal a lo universal: existencialismo y muerte en la poesía de David Rosenmann-Taub”. Lo singular y lo universal en la poesía de David RosenmannTaub. México/Paris: RILMA 2/ADEHL, 2012. 85-94.

Cruz, San Juan de. Cántico espiritual. Madrid: Orden de las Carmenlitas Descalzas, 1579. Varias reediciones.

Durrell, Lawrence. El cuarteto de Alejandría. Bogotá: Debolsillo, 2009.

Fernández, Teodosio. "El objetivo es la verdad: reflexiones sobre la poesía de David RosenmannTaub". Lo singular y lo universal en la poesía de David Rosenmann-Taub. México/París: RILMA 2/ ADEHL, 2012, pp. 111-124.

Guzmán, Jorge. Diferencias latinoamericanas. Santiago de Chile: Departamento de Estudios Humanísticos, 1986.

Lago, Tomás. Ocho nuevos poetas chilenos. Santiago de Chile: Zigzag, 1939.

Tres poetas chilenos. Santiago de Chile: Cruz del Sur, 1942.

Monteleone, Jorge. David Rosenmann-Taub. Multiverso. Selección y estudio preliminar. Buenos Aires: Mansalva, 2012.

Nómez, Naín. "La poesía de los cincuenta: aproximaciones a la modernidad en disolución". Taller de Letras 34. Santiago de Chile: Revista de la Facultad de Letras de la Pontificia Universidad Católica de Chile (2004): 85-96. 2006.

Antología crítica de la poesía chilena. Tomo IV. Santiago de Chile: Lom Ediciones,

"La poesía de los cincuenta en Chile y España: escorzos y aproximaciones". Mapocho. Revista de Humanidades 60. Santiago de Chile: DIBAM (2006): 391-402.

"Utopías de la memoria: búsqueda de la trascendencia en la poesía de David Rosenmann-Taub”. Aisthesis 50, Revista Chilena de Investigaciones Estéticas. Pontificia Universidad Católica de Chile (2011): 172-188. 
"Cortejo y epinicio de David Rosenmann-Taub: exorcismos de la memoria". Lo singular y lo universal en la poesía de David Rosenmann-Taub. México/París: RILMA 2/ADEHL (2012): 13-32.

Paz, Octavio. Los hijos del limo. Del romanticismo a la vanguardia. Barcelona: Biblioteca Breve, Seix Barral, 1974.

Ramos-Izquierdo, Eduardo, editor. Lo singular y lo universal en la poesía de David RosenmannTaub. México/ París: RILMA 2/ADEHL, 2012.

Rojo, Grínor. Dirán que está en la gloria (Mistral). Santiago de Chile: Fondo de Cultura Económica, 1997.

Rosenmann-Taub, David. Cortejo y epinicio. Santiago de Chile: Editorial Cruz del Sur, 1949. “El raudal”. Cuaderno de poesía. Dinora, 1962. En La poesía de Rosenmann-Taub. Sitio Fundación Corda, 2018. Cortejo y epinicio. Reedición corregida. Santiago de Chile: Lom Ediciones, 2002. El mensajero. Cortejo y epinicio II. Santiago de Chile: Lom Ediciones, 2003. La opción. Cortejo y epinicio III. Santiago de Chile: Lom Ediciones, 2011. 2013. El zócalo. Cortejo y epinicio I. Segunda Edición. Santiago de Chile: Lom Ediciones, La noche antes. Cortejo y epinicio IV. Santiago de Chile: Lom Ediciones, 2013.

Salvador, Álvaro y Erika Martínez, editores. Me incitó el espejo. David Rosenmann-Taub. Barcelona: DVD Ediciones, 2010.

El duelo de la luz (Antología de Cortejo y epinicio) de David Rosenmann-Taub. Valencia: Pre-Textos, 2014.

Tapia, Patricio. "Contra la improvisación”, Entrevista a David Rosenmann-Taub en El Mercurio, Artes y Letras (20 de noviembre) 2005, p. E 4-5.

Yurkievich, Saúl. Fundadores de la nueva poesía latinoamericana. Barcelona: Editorial Ariel, 1984. 